\title{
Linguistic Intensification and its Role in Interlingual Translation of Speech Acts between English and Arabic
}

\author{
Ali Abdullah Mahmood \\ Department of English, College of Education for Humanities, University of Diyala \\ Al-Rasheed Street, D.25, Baghdad, Iraq \\ E-mail: dralimah.75@gmail.com
}

Doi:10.7575/aiac.alls.v.6n.3p.23

Received: 01/01/2014

URL: http://dx.doi.org/10.7575/aiac.alls.v.6n.3p.23

Accepted: 12/03/2015

\begin{abstract}
This paper tries to answer two questions: first, how far do intensifiers in English have the capability to fulfill linguistic intensification in order to achieve the communicative action between the speaker and the listener? Second, to what extent do linguistic characteristics of intensifiers influence translation of locutions of linguistic intensification carrying certain speech acts between English and Arabic? In relation to 'hyperbole' as one form of linguistic intensification, English and Arabic do not show similar attitudes in expressing their hyperbolic forms though in certain cases they achieve similar functions of exaggeration. The transferring of these intensifiers within the locutions of speech acts is intensely adding some new meaning to the communicative structure being conveyed from the source language to the target language. These intensifiers are intrinsic pragmatic bearers of 'genuine' speech acts as 'impressing', 'insulting', 'persuading' and 'praising' which can be entirely fathomed if the macro-illocutionary force of the communicative utterance is thoroughly evaluated and recognized.
\end{abstract}

Keywords: linguistic intensification, interlingual speech acts, English, Arabic

\section{Linguistic Characteristics of Intensifiers}

Intensifiers (amplifiers in Quirk et al.'s (1987) terminology), degree modifiers, or focusing adverbs form an open class of English grammar. Degree adverbs develop from content-foregrounding expressions to items highlighting configuration, degree, boundedness and scale (Mendez-Naya, 2008). New adverbial items frequently come into use through 'delexicalization' process in which certain intensifiers have lost their original meanings. In his investigation of the diachronic study of 'intensifiers', Partington (1993:177) found out that "a number of frequent ones [intensifiers] like very and utterly have undergone a shift from modal to intensifier." Bolinger (1982: 23) puts this case the following way: "Virtually, any adverb modifying an adjective tends to have or develop an intensifying meaning". On the other hand, the meanings of some intensifiers became stale and need to be replaced by newcomers which are liable to change and be hyperbolized. Therefore, the intensification system of English has the ability to refresh its cells through the perpetual recycling process of its intensifiers due to the dissipation of their original meanings as a result of their overuse through the course of time.

\subsection{Semantic features of intensifiers}

Intensifiers are classified into two subdivisions: amplifiers and downtoners. "They are so labeled because they are considered to operate on certain linguistic elements to magnify the degree of intensification or to amplify certain qualities" (Tao, 2007: 5-6 ). For the sake of limitation of the study and for brevity, our paper deals only with 'amplifiers'. Quirk et al. (1987: 590-91) listed the following two subsets under 'amplifiers': maximizers, e. g., absolutely, altogether, completely, entirely, extremely, fully, perfectly, quite, thoroughly, totally, utterly, in all respects, and the intensifying use of most. Boosters, e. g., badly, bitterly, deeply, enormously, far, greatly, heartily, highly, intensely, much, severely, so, strongly, terribly, violently, well, a great deal, a good deal, a lot, by far, exclamatory how, and the intensifying use of more. However, such classification may not introduce a clear-cut boundary between the subtypes of 'amplifiers', and that is why Quirk et al. (1987: 590) call it a rough semantic distinction "because (i) the varying effects of intensifiers represent a semantic gradient, which is obscured by a clear-cut division into classes; (ii) some intensifiers are sometimes used for different effects; and (iii) speakers vary in their use of intensifiers." For instance, speakers may mix levels between the maximizer utterly and the booster violently in terms of their semantic force when they come medially in the sentence:

(1)They $\{$ utterly, violently $\}$ detested him.

It is worth mentioning that there are some semantic restrictions on the predominant use of these amplifiers with certain English verbs: I entirely agree... We badly need, want... I completely forget... They greatly admire, enjoy... It has also been revealed that certain intensifiers such as (fully justified ), (greatly appreciated), (perfectly acceptable) bond most strongly with verbs of favorable implications, while others such as (heavily polluted), (totally illogical), (utterly desolate) collocate with verbs of unfavorable implications (Quirk et al.,1987: 593 ). However, these restrictions are not 
limited to verbs but also to some adjectives since there are strong collocational relations between certain intensifiers and certain adjectives (e.g., absolutely dead, extremely rare, very good, etc.).

The semantic features indicate that when amplifiers denote the upper extreme of the scale, they are 'maximizers'; whereas denoting a high degree on the scale indicates that the amplifiers are 'boosters'. Examples are:

(2)The dean is absolutely right. (maximizer)

(3)The soldier is severely injured. (booster)

This justification is better explained by Biber et al. (1999: 554) saying that "degree adverbs describe the extent to which a characteristic holds. They can be used to mark that the extent of degree is either greater or less than usual or than that of something else in the neighboring discourse." In this sense, intensification is scalar in that it shows degree of linguistic intensification of a certain semantic content. However, a semantic test can be applicable to know whether the intended intensifiers are really 'amplifiers' or not. This is done through alternative negation with 'to some extent ' as in the examples below from Quirk et al. (1987: 590):

(4) He didn't ignore my request completely, but he did ignore it to some extent.

(5) They don't admire his music greatly, but they do admire it to some extent.

In both subsets, "amplifiers scale upwards from an assumed norm", and such scaling needs that the collocated items with which thaese amplifiers come are gradable (ibid). Thus, this type of adverbs can fill various slots on the degree scale, and this behavior is associated with the boundedness of the four parts of speech: adjective, adverb, verb or noun, i.e., when they describe non-gradable adjectives, for instance, they show highest degrees on the scale, but various degrees are marked on the scale when gradable adjectives follow these adverbs:

(6) He was left entirely alone after death of his wife. ('Alone' is non-gradable adjective.)

(7) Mary is quite young.

(8) Jane is very nice. ('Young' and 'nice' are gradable adjectives.)

On her part, Paradis (1997:158) stated that on semantic grounds, "the gradable feature in the adjective must harmonize with the grading function of the degree modifier in terms of totality and scalarity to make a successful match." However, vagueness of certain intensifiers may break the criterion of gradability of adjectives in certain contexts. For example, the intensifier quite expresses highest degree on the scale, but its semantic function is vague in the following examples:

(9) She was quite correct. (10) She was quite good.

In (9), Quite means 'completely' showing highest degree, while in (10) quite means 'very', showing medium to high degree.

On the other hand, gradability can be used as an instrument to measure the function of intensifiers. "Amplifiers cooccur only with gradable verbs, and when adverbial items of the same form co-occur with non-gradable verbs they do not function as amplifiers, but as quantifiers, duratives, or frequentatives, or as process adjuncts":

(11) She drinks milk a lot. [often]

(12) He will judge us severely. [in a severe manner] (Quirk et al., 1987: 594- 95)

\subsection{Syntactic features of intensifiers}

Intensifiers, like other word classes, have many syntactic functions. One of their syntactic features is that they are modifiers which add new information to another item in the context such as an adjective, an adverb, a noun, a verb or a prepositional phrase:

(13) His answer was completely unclear.

(14) She behaved very differently from her mother.

(15) Mary, you are quite a beauty.

(16) I entirely agree with your justification.

(17) Indeed, she is quite of the teacher's opinion.

In his investigation of the adverb absolutely in discourse, Tao (2007: 6) gives the following remark which can be used as a yardstick to measure the syntactic reliability of amplifiers in certain syntactic patterns: Like many amplifiers, absolutely exhibits a number of syntactic and semantic properties typical of an adverb. It is often used, for example, in a preverbal (including adjectival) position and forms a syntactic sequence as indicated in the following: Adverb(absolutely) + Adjective (Phrase)/ Verb (Phrase). To illustrate this use, he (ibid) gives the following examples:

(18) High school was absolutely great.

(19) We came up with four. None are absolutely controlling those.

(20) You absolutely have to confront the belief that ...

Thus, in (18) absolutely modifies the adjective 'great', and in (19) and (20) it modifies simple and complex verbal expressions respectively(controlling those and have to confront the belief). The previous explanation shows that there are certain syntactic restrictions on the use of the intensifier absolutely which can prevail to other amplifiers with 
varying degrees. Thus, the occurrence of intensifiers is subject to special syntactic criteria. In addition to their function as adverbials by adding information to the clause in $(19,20)$, they describe most of the word classes of English. In fact, they are considered the most typical adjective modifiers which can be used to measure the degrees of adjective qualities from highest degree and medium to high degree like 'completely finished' and 'fairly narrow'.

Among the other syntactic features of amplifiers, Quirk et al. (1987: 596) list their "coming within the scope of predication pro-forms or ellipsis":

(21) She hoped that he would search the room carefully, and he did so.

(22) He often behaved prudently, but he did not always behave so.

(23) Are they paying you for the work? Yes, they ARE (doing so.)

On the other hand, "amplifiers cannot be the focus of a cleft sentence", though for some people, they can be part of such sentence when they are modified or being interrogative / negative (ibid: 596-97):

(24) *It was completely that he ignored your request.

(25) ? Was it completely that he ignored your request?

(26) ? I know it wasn't entirely that he agreed with us?

Syntactically speaking, amplifiers do not accept the interrogative process as part of the answer to How-question unless the verb element of that question is used for general evaluation. Consider the following examples from Quirk et al. (ibid: 597):

(27) * How do they admire his music? (They admire it) \{Very much., Greatly.

(28) How do you like it? (I like it) \{Very much.,? Greatly.

\section{Linguistic Intensification and Hyperbole}

Hyperbole is a linguistic phenomenon prevailing in all languages, but languages differ in their structures which embrace this process of description in everyday speech among their users. In the daily routine, intensification contributes much to keep the linguistic communication in a certain condition via arousing eagerness on the part of the hearer to share the intended meaning with the speaker. Therefore, intensification is considered as a good representative in making the meaning more effective and adding more enthusiastic features to the utterances of the speaker. This definitely is one way of expressing hyperbole through different locutions and facets of a particular language. This implicitly means that hyperbole is a stylistic means of description through which the speaker describes things with the uppermost or lowering degrees of exaggeration to the extent that the descriptive event is either far-fetched or impossible, especially in literary texts (my translation) (Al-Hashimi,1963: 380). This can be illustrated in the following example from The Holy Qur'an (n. d., [Surat Al-Baqarah II] (The Cow), Aya No. 260): (29) [... Oumma ?udçuhunna ya?tiinaka saçyaa] ([...] and call them, they will come to you in haste. (Translation of the Meanings of The Noble Qur'an in the English Language,1999) In Arabic, the gerund cannot function as a modifying head for the predicate, the adjective, and the adverb unless it is used for the purpose of hyperbole. Therefore, the gerund [sacyaa] (literally: quick pace) is a mere verbal action describing how the dead birds were changed into living creatures as a sign to make the Prophet Abraham believe in God. Of course, our minds cannot grasp the idea (being coated with extreme exaggeration), and it is impossible unless it is a miracle of God. Moreover, the translators use the prepositional phrase 'in haste' instead of a degree adverb for the Arabic gerund [sacyaa] to express hyperbole.

It is clear that some intensifiers develop hyperbolic functions, and this is due to the natural instinct of human behavior to state, assert, emphasize or sometimes exaggerate certain speech in order to reinforce his status and achieve a goal among individuals of a particular community. This is done through association with certain adjectives and hyperbolic forms such as absolutely marvelous, completely appalling and totally intolerable.

\section{Linguistic Intensification and Speech Acts}

Linguistic literature has showed much interest in how users of English decrease or increase the illocutionary force of their actual utterances. However, the most prevailing speech acts which linguistic intensification can carry are 'impressing', 'insulting', 'persuading and 'praising'. Below are some examples justifying the agent's communicative intentions:

(30)"I do so recognizing that change cannot happen overnight."(impressing: President Obama addressing Egyptians)

(31)"Yes, your mistakes are completely unbearable."(insulting: a manager to a worker)

(32)"The house is extremely beautiful."(persuading: an agent of housing to a customer

(33)"You are awfully intelligent."(praising: a teacher to a student)

It is evident that speech acts are subject to socio-cultural divergences since languages differ in their structural systems. Speakers exchange a sort of communicative intention to achieve the illocutionary aims using different structures of intensification. In the example (34) Pity, you weren't out; we had quite a good day, the use of the intensifier quite before the (adjective + noun) has the implicature that the speaker reassures the addressee of having a good time, and thus impressing the idea of feeling sad for the sufferings of the addressee because he didn't go out to have an enjoyable time with the speakers' group. In this case, quite, though scales the sense of the adjective downward from an assumed norm, shows the speaker's evaluation of the speech act. Here, the speaker's evaluation of the communicative act as 'quite good' 
to feel pity for the listener as his staying in is without benefit, and he had better accompany them to share an enjoyable time with them. Really, the above locution is quite different from the communicative structure having no intensifier. It will become a mere conversational unit of a particular semantic type.

A speech act conveyed on the back of the linguistic carriage of intensification depends on how the communicator thinks of the utterance and how the language of that utterance is used in an appropriate context. Therefore, when certain linguistic items are frequently used to perform certain communicative acts, they become conventionally related to the illocutionary forces of those acts. Consider the following English soundtrack from the British film of Stanley Kubrik, Eyes Wide Shut (1999) (cited in Bruti, 2006:193): (35) Gayle: Do you know what's so nice about doctors? Bill: Usually a lot less than people think. Gayle: They always seem so knowledgeable. Bill: They are very knowledgeable about all sorts of things.

All the intensifiers are used in the dialogue for the purpose of 'praising'. English very modifies relative-standard gradable adjectives, while boosters so and $a$ lot are used with non-gradable adjectives. Nevertheless, they all show the speaker's attitude to establish rapport and to achieve a better social effect in terms of solidarity on the part of the hearer. On the basis of socio-pragmatic values, the speakers 'Gayle and Bill' express their admiration and praise or even their appreciation of doctors' work and thus achieved the perlocutionary effect of 'persuading' the reader of their intention towards a special group of persons in the society. This type of social communicative acts would not be such if their locutions are set without the existence of the mentioned intensifiers. In addition to the syntactic and semantic functions of these intensifiers, the pragmatic function of 'very', 'so' and 'a lot' is to serve as a fixture of the speakers epistemic meaning which in turn increases their trust and confidence in the veracity of their utterances.

On the other hand, if Jill is addressing his partner saying (36) You're totally wrong, he expresses, in certain context, his intention to perform the illocutionary force of 'assertion' through the intensive use of totally. Totally maximally intensifies the meaning of the adjective 'wrong'. Nobody can really say that the partner recognizes Jill's communicative intention as a 'praise' or a 'request', but instead, it is understood as an 'insult'. This is due to "the relevant linguistic and contextual conditions that allow the hearer to recognize the illocutions the speakers intend to communicate with their utterances"(Lenci,1994:115).

\section{Translation of Linguistic Intensification}

As semantic and pragmatic bearers of some linguistic and inferential meaning, intensifiers pose some problems in processing the information through their rendition into the target language (TL). However, translation of utterances including intensifiers can be done in spite of the frequently subtle differences between the two linguistic utterances in English and Arabic. Strictly speaking, rendition of these utterances should contain all the linguistic information of the intensifiers in the source locutions plus that related to the relevant contextual effects resulting from the translator's inferential interpretation in his competent reading of the intensifiers' locutions, first. Second, the reader's ability to recognize the information of the target locution in a way contextual effects produced by the use of the intensifiers in the reader's representation of both locutions should be recovered.

\subsection{Translation of hyperbolic forms of intensifiers}

English and Arabic differ in marking their hyperbolic forms in that English expresses exaggeration in terms of utterances; whereas Arabic uses a set of derivative items carrying hyperbolic functions. Suppose that a translator comes across this utterance: (37) He hit him bitterly. [darabahu darban mubarrihan]. It is obvious that there is a lack of literal-equivalence relation between the source utterance and the target one. It seems to us that Arabic rendition marks a higher degree of intensification than English, and thus achieved a better hyperbolic function than the locution of the source utterance. The Arabic expression [darban mubarrihan] (literally: hitting bitter) suggests an uppermost degree of intensification and emphasis that the English intensifier bitterly lacks. This is due to the morphological and phonological structures of the new derivatives. Through the process of restructuring the verbal noun [darban] (hitting) from the trilateral dynamic verb [darab] (hit), the addition of the phonological unit [-an] to indicate the accusative function and the deletion of the case marker for the past tense $[a]$ (fatha) intensify the meaning to result in exaggeration (see Table 1).

The adjective [mubarrihan] (bitter) also carries a high degree of intensification. Thus, the two Arabic items [darban mubarrihan], compared to the English booster bitterly, carry the hyperbolic function which indicates the real effects produced in our minds as native speakers of Arabic more than the intended effects of the English hyperbole conveyed by the booster bitterly signifying less than maximal intensity. Moreover, the Arabic translator may sacrifice certain syntactic structures for the sake of achieving the intended hyperbolic function of the source language (SL) into the TL. Consider the following example taken from a political speech delivered by the late Egyptian President Jamal Abd-ulNasser in 1958 (cited in Shunnaq, 2000: 221):

(38) [jiilunaa qaatala qitaalan mariiran] (Our generation has fought ferociously.) Here, the translator avoided repetition of the two related Arabic lexical items [qaatala qitaalan] (literally: fought fight) where the 'cognate accusative' [qitaalan] derives from the verb [qaatal] because, as he believes, "English does not favor literal renderings for the cognate accusative"(ibid: 222). Of course, this would be an ill-formed English sentence if it is translated literally; whereas the Arabic 'functional repetition' in the above sentence sounds pleasant and more interesting to the ear of the native speaker of Arabic, and thus it pragmatically creates a hyperbolic pattern of emotion and an aspect of aesthetic value in upgrading the phonological rhythmic units to the surface level of the utterance. But one should note that the hyperbolic function of the English version is not as equivalent as the Arabic counterpart because the semantic content of 
the verb (fought) and the booster (ferociously) cannot compensate the meaning of the Arabic verb [qaatala] + the cognate accusative [qitaalan] + the adjective [mariiran] (ferocious) for which the translator renders it into an English degree modifier (ferociously) in order to achieve a similar hyperbolic function of the SL in the TL.

Table 1. Key Symbols to Transliteration of Arabic Words

\begin{tabular}{|c|c|c|c|c|c|c|}
\hline \multirow{2}{*}{$\begin{array}{l}\text { Arabic } \\
\text { Letters }\end{array}$} & \multicolumn{2}{|c|}{ Transliteration } & \multirow{2}{*}{$\begin{array}{l}\text { Arabic } \\
\text { Letters }\end{array}$} & \multicolumn{2}{|c|}{ Transliteration } & \multirow[t]{2}{*}{ Case Markers } \\
\hline & $\begin{array}{l}\text { Phonemic } \\
\text { symbols }\end{array}$ & $\begin{array}{l}\text { Normal } \\
\text { letters }\end{array}$ & & $\begin{array}{l}\text { Phonemic } \\
\text { symbols }\end{array}$ & $\begin{array}{l}\text { Normal } \\
\text { letters }\end{array}$ & \\
\hline hamza(s) & $?$ & & 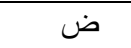 & $\underline{\mathrm{d}}$ & $\mathrm{dh}$ & Short vowels \\
\hline ب & $\mathrm{b}$ & & b & $\underline{t}$ & & fatha $=\mathrm{a}$ \\
\hline$ت$ & $\mathrm{t}$ & & ظ & $\underline{\mathrm{Z}}$ & & $\underline{\text { damma }}=\mathrm{u}$ \\
\hline$ث$ & $\Theta$ & th & $\varepsilon$ & C & & kasra $=\mathrm{i}$ \\
\hline 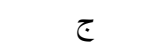 & $\mathrm{j}$ & & $\dot{\varepsilon}$ & $\overline{\mathrm{g}}$ & gh & \\
\hline$\tau$ & $\underline{\mathrm{h}}$ & & ف & $\mathrm{f}$ & & Long vowels \\
\hline$\dot{\tau}$ & $\mathrm{x}$ & $\mathrm{kh}$ & 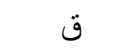 & $\mathrm{q}$ & & case,no, gender \\
\hline د & d & & ك & $\mathrm{k}$ & & ألف = aa \\
\hline$\dot{j}$ & ð & & 」 & 1 & & و واو =uu \\
\hline J & $\mathrm{r}$ & & 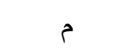 & $\mathrm{m}$ & & ياء = ii \\
\hline j & $\mathrm{z}$ & & ن & $\mathrm{n}$ & & Diphthongs \\
\hline 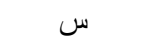 & $\mathrm{s}$ & & $ه$ & $\mathrm{~h}$ & & أي =ay \\
\hline ش & $\check{\mathrm{s}}$ & sh & g & $\mathrm{w}$ & & only no\&gender \\
\hline ص ص ص & $\underline{\mathrm{S}}$ & & ي & $\mathrm{y}$ & & أو = aw \\
\hline
\end{tabular}

The semantic content and the situation are inseparable in expressing hyperbole in the following utterance from Colston \& Keller (1998: 500): (39) This is the most dreadful situation that anyone could ever be in (in relation to the unexpected situation Kerri was in when she broke the strings of her guitar before she was to perform). Here, more intensification is conveyed by the speaker to the extent it carries more exaggeration when it is universally measured with 'anyone could ever be in'. Such an outweighed utterance may not convey similar hyperbolic equivalent into Arabic: [haaðaa lmawqifu huwa l-?ą̧zamu fadaaçatan ?llaði mumkinu ?ay-yamurru bihii šaxśm-maa]. Most' is the highest degree of intensification in English. Its rendition in Arabic is [?al?ą̧zamu] which collocates with [fadaaçatan] (dreadfulness). This item suggests a degree of intensification and emphasis less than in English. The English and Arabic versions should trigger equivalent representations, but unfortunately, the utterance in Arabic would not bear an equivalent hyperbole to the English utterance because of the real difference in the use of intensifiers between them. This suggests that though translation of hyperbolic forms cannot be approached as a case of equivalent entities, linguistic structures of intensification differ in the way of expressing such functions. It seems quite evident that both utterances have similar implications, but they differ in the degree of intensification which crucially involves some implicatures promoting the speaker's attitude to the highest degree on the assumed scale. It is the English one, compared to Arabic, which denotes this sort of proposition. Thus, the locution which carries the highest degree of intensification is supposed to carry the highest degree of exaggeration (hyperbole). In translation, the intensifier used represents the 'booster' in Arabic rather than the 'amplifier' in English which indicates the means through which the speakers prefer going to extremes. Colston and Keller (1998: 502) emphasize this point saying that "people tend to associate and equate hyperbole with amplification, but rarely with reduction or attenuation." These all contribute to an effective process of translation through which syntactic, semantic, phonological and pragmatic configurations of the TL are interwoven to be understood by the translator, first, and sensed by the target reader, second.

In Arabic, hyperbolic expressions usually describe moods and feelings of a person, and thus mark figurative language. Therefore, when translating English hyperbolic expressions including intensifiers into Arabic, they are more explicit as body-like nouns than English because English prefers a more abstract information: (40) His mood was much better. [?inbas atat ?asaariirahu]. (41) She was deeply shaken. [?intafadat bikulli jawaarihihaa] (Examples are from Mahfoudh, 1972: 24.) The Arabic versions focus on some events concretely described as [?asaariirahu ] (parts of a human body) and [bikuli jawaarihihaa] (the six senses), while the English locutions concentrate on the hyperbolic functions of the intensifiers much and deeply which seem to be literally absent in either case of the Arabic version. There is an obvious lack of literal equivalence relation between the SL and the TL versions. This can be clearly stated that although no intensifiers are mentioned in the Arabic rendition, there is still an achievement of the linguistic intensification in general and hyperbole in particular through other lexical items to evoke the same response.

One should note that the translator's adherence to the linguistic components of the TL or SL rather than its cultural norms leads to misrepresentation of the source utterance as rather uneven. This can be clearly stated in two Arabic structures from Hussein (n.d., pt.1: 121) translated differently by Paxton (Hussein,1997[1932]: 71-72): (42) [...?altiflatu tasiihlu siyaahan munkaraa] (... the little girl began to utter horrible cries.). (43) [...?altiflatu tartaçidu ?irtiçaadan munkaraa] (... the little girl quivered horribly.) In both examples, the word order of the Arabic sentence is SVOA(dj.). In (42), the translator uses the adjective 'horrible' as an equivalent to the Arabic adjective 'munkaraa' which describes the cognitive accusative 'siyaahan' (cries) in either case. Here, the adjective 'horrible' marks high intensity to show the intended hyperbolic function of the source utterance. It is worth mentioning that the linguistic intensification 
of the SL is expressed by the whole structure of the verb [tasiih $u$ ] (began to utter) + the object [siyaahan] (cries) + the adjective [munkaraa] (horrible) opposite to the TL where only the adjective 'horrible' represents the hyperbole. In (43), though a similar syntactic structure to (42) is uttered, the translator compensates the whole SL structure with the booster horribly to achieve linguistic intensification as a means to the TL hyperbolic pattern. It is to be concluded here that, in translation, the intensifier is not the only tool for measuring linguistic intensification. Instead, there are other linguistic elements such as the adjective, the noun, the verb, and the prepositional phrase, which can, to a certain extent, achieve high or low intensity leading to distinguished hyperbole on the part of the target readers. Thus, a synthetic mediated process of translation is required to keep the potentials of the source utterance untouched and to supply a macropragmatic and micro-syntactic and lexical dimensions of the target utterance to guarantee functional equivalent and avoid some linguistic incongruence which may form difficulty in translation.

\subsection{Translation of interlingual speech acts into Arabic}

In this section, we are confined with four main speech acts carried by locutions of the linguistic intensification in English, and how these acts are transmitted into Arabic. A similar intention and/or an effect of the communicative act should be aimed at in rendition of these locutions into Arabic. A locutionary act (44) I'm really eager to know your reaction [haqiiqatan ?anaa tawwaqun li-maçrifat ?istijaabatika], has the illocutionary force of 'impressing' someone to know his response towards a certain case. The main function of the booster really is to emphasize the speaker's intention and to elaborate on the act's core meaning. The most important thing is that the speaker and the hearer are within the same communicative situation, i.e., they understand each other, and that the hearer is able to recognize a set of assumptions by which the speaker can formulate his structure of the utterance. However, the use of the English intensifier really is translated into Arabic as a noun [haqiiqatan] (truth), deriving from the degree modifier [haqqan] (really / truly), affecting the action of the verb. The non-gradable adjective 'eager' is translated into Arabic as a hyperbolic form having the meter 'faç̧aal' [tawwaq] (eagerness) which strengthens the illocutionary force of the speaker's utterance and achieving his competing perlocutionary effect. When a similar effect is produced in the TL hearer/reader, the rendition of this intensification locution is a 'saving act'.

On the other hand, it is common in daily conversation that speakers used to praise some other persons or hearers by using intensification locutions, and there must be some effects on the participants of the conversation. In the example (45) of Tintin Comic Series (cited in Attamimi, 2011: 93), Detective Thomson to Captain Haddock: "Well, You're very wise not to go on such a wild goose chase! ", the illocutionary force is 'praising' where Detective Thomson's intention is read and understood as such. The use of the booster very actually adds some intensive meaning and 'truthfulness' to the locutionary act of the SL. The Arabic translator has to look for a similar reception of SL speech maintaining the degree of the information required for such rendition represented by the English booster very: [hasanan ?anta hakiimun jiddan fii çadam Jihaabika fii mutaaradati ?awzatin barriyyatin ka-haaðihi]. The interpretation of the Arabic locution concentrates on the intensifying use of the degree modifier [ jiddan] (very) and the increasing of the sense of vouching for truth of what the speaker has said. Moreover, the original meaning of very is present in the TL version to reinforce the inchoative use of negative effects (not to go on such ...) and to emphasize the idea of 'wisdom' on the part of the addressee. What seems important is that the locutions in English and Arabic show some resembling effects in the SL and TL readers.

The translator of the Arabic locution may fully reflect a similar effect of the English locution if s/he finds alternative expressions of Arabic intensifiers that sound familiar to the Arabic hearers/readers. To illustrate, consider the following example: (46) What a truly hateful man you are ! [kam ?anta rajulun haquud]. Though a speech act might be interpreted differently by the hearer, the locution in (46) carries the illocutionary force of 'insulting' depending on the high degree of intensification which the maximizer truly adds to the sense of the adjective 'hateful'. This kind of speech act as 'Expressive' states what the speaker feels towards a listener, and his intention is clear to the extent it might make the listener feel similarly (Searle,1976:10). However, the Arabic translator cannot rely solely on the equivalent structure of his native language. Instead, he has to look for other semantic and pragmatic resources in Arabic. The intensifying use of the exclamatory 'what' and the maximizer truly with the gradable adjective 'hateful' form a special propositional mould leading to a successful communicative act. These words are dependently chosen so they can convey the meaning of intensification within a real combination of that context and relevance. In Arabic, the use of the adjective [haquud ] (full of hatred), (as one form of hyperbole having the meter façuul) and the interrogative particle $[\mathrm{kam}]$ form a rhythmic unit of linguistic intensification which carries the illocutionary act of 'insulting'. Definitely, the rendition of such locution has the effect of 'insulting' some other person, no matter how structurally the target and the source languages are close to each other.

A good example of 'persuading' is taken from Obama's speech after his second election as a president of America (The Guardian, Wed., 7 Nov., 2012):

(47)"We may have battled fiercely, but it's only because we love our country deeply, and we care so strongly about its future." [mumkin ?an natašaajara bi-hidda faqat li-?ananaa nuhibu baladanaa min l-?ą̧maaq wa-nahtamu kaӨiiran wa-biqquwatin li-mustaqbalihi]. The speaker expresses a psychological state of pleasure, describing a particular case in his country, believing that what is achieved is a special performance related to the morals of American society. In fact, it is a special utterance in a special occasion and has a special intention to get a special effect. The communicative intention underlying Obama's locution is to 'persuade' the audience (Americans in particular and world -wide's massmedia in general ) that the American election is the best in the world. Such a perlocutionary effect might be achieved with varying degrees of influence. "Sometimes, the positive impression intended by the speaker is interpreted wrongly 
by the hearer "(Attammi, 2011: 88). The hearers may feel angry (his rivals or opponents), happy (his followers) or neutral (others). It depends on the audience trust, confidence, satisfaction, knowledge, relevant linguistic and contextual conditions and their various emotional responses towards what the President has said. However, the use of the boosters deeply, fiercely, so and strongly explicitly adds more emphasis to the implicit intensive meaning stressed by the President, and thus reinforces the attitude of the speaker to reach greater affiliation with his citizens. "President Obama's commissives consist of modal verbs and infinitive clauses to project volition and intention"(Josiah and Johnson, 2012: 261).

Realizing the speaker's illocution on the part of TL hearers/readers requires certain conditions involved in the Arabic rendition of the speaker's utterance. The communicative act may fail when the TL hearer/reader is unable to recover any interpretation consistent with the intended relevant information of the locution. But definitely, neither recognition of the illocutionary force of the SL, nor the realization of the perlocutionary effect (persuading) on the SL audience are exactly similar to the TL ones. This is due to different situational contexts and cultures, communicative expectations, interpretation of the TL hearers/readers, on one hand, and to the translator's competence to correctly understand the syntactic and semantic factors of the locutionary act in the SL from a pragmatic point of view, on the other. Bernardo (2010:114) supports this explanation stating that "A single illocutionary act may give rise to several different perlocutionary acts."

\subsection{Factors influencing translation of linguistic intensification}

The translator may face difficulties in translating locutions of English intensification into Arabic. Among them are:

\section{(a)vagueness of certain intensifiers}

The vagueness of certain English intensifiers is a real obstacle in translation of these linguistic items into Arabic. A sentence like (48) The goods are quite expensive nowadays, could have two interpretations in English depending on the way the degree modifier quite is treated whether 'downtoner' or 'amplifier'. It could mean (a) 'They are very expensive' in some context, and (b) 'They are rather expensive', in other context, taking into consideration the intonation pattern used, i.e., quite receives high pitch level when it means very and low pitch level when it means rather ( Mustonen, 2010: 16). Then the Arabic renditions would be either (a) [?alsilaçu gaaliyatun jiddan haðihi-il?ayyaam] which has the contextual effect of truth condition, or (b) [?alsilaçu gaaliyatun nawşammaa haðihi-il?ayyaam] which does not contribute to the truth conditional meaning of the utterance. The equivalent Arabic intensifiers are not equal in the modifying degree, and they seem quite different in achieving a high degree of intensity on the scale in (a) and a lower degree in (b) which is not similar to the effect produced in our minds of the English intensifier rather. It seems to us that the second proposition of English version marks a higher degree of intensification than the Arabic one. This may lead to misinterpretation of the speech act on the part of the TL addressees which in turn results in a false perlocutionary effect of the intended illocutionary force. Such vagueness of meaning raises a question of how to account for all SL nuances of meaning in Arabic as a TL.

A group of intensifiers including awfully, dreadfully and terribly originally collocate with modifiers having negative connotations in old English as "so as to excite terror or dread" (The Oxford English Dictionary, 2000); whereas in modern English, they collocate with positive adjectives like 'glad', 'good', 'kind', 'happy' and 'well', as in the following citations from Partington (1993: 183-84):

(49) I'd be most awfully grateful if you could spare me a moment...

(50) They're dreadfully nice. You must meet them, Maria.

(51) So I was terribly thrilled by this ...

The above group of degree modifiers, having a negative semantic content, is supposed to collocate with negative submodifiable items. However, the new collocations with positive adjectival heads put a lot of burden on the translator's

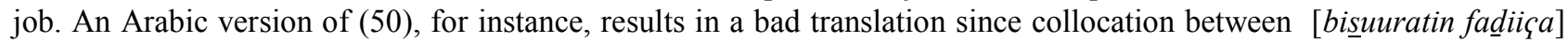
(dreadfully) and the adjective [lutafaa?] (nice) does not match in Arabic: [maariyaa, yejib ?an tuqaabiliihim ?innahum ?ašxaașun lutafaa? biśuuratin fadiiça]. At an utterance level, the translator should pay considerable attention to a full comprehension of what can be inferred from it, and to the syntactic, semantic and pragmatic requirements of the TL and its culture. "A literal translation, though preserving the author's wording, loses the nuances of the original text" (Mahmood and Abdellatif, 2010:146). Therefore, the translator should look for an alternative rendition which sounds logical to the TL readers' representations for sentence (50): [maariyaa, yajib ?an tuqaabiliihim ?innahum ?ašxaasun lutafaa? Jiddan]. This non-literal and non-equivalent type of translation requires from the translator a pragmatic competence and a knowledge of the context with which several layers interact in order to engender an intended effect on its TL readers. The most important thing is that the amplifying effect which certain intensifiers can cause in the SL readers is somehow similar to that effect in the TL readers.

\section{(b) boundedness of the modifying heads}

Another difficulty in translation of intensifiers is the 'boundedness' of their modifying heads. Collocation with gradable adjectives have a special meaning different from those with non-gradable ones. Utterances like (52) a. Jane is quite nice. b. Jane is quite motionless, give different semantic prosody depending on the intensifier's following adjectives. Quite in (a) carries the meaning 'to some extent'; whereas in (b) it has the meaning of completely. In translation from English into Arabic, this intensifier is problematic since the adjectival heads are the linguistic elements 

tamaaman].

\section{(c) fuzziness of the meaning of intensifiers}

Fuzziness of the meaning of intensifiers can cause a problem to the Arabic translator since there is no clear cut-line to mark the meaning of each intensifier, and there is no obvious reason of why this intensifier, for instance, is more suitable than the other in certain context unless intuitively reasoned. According to Carston (1991), it is true that the degree modifier sometimes show fuzzy, underdetermined nature, typical of many expressions in the linguistic code. "Fully, completely and totally share a similar meaning which illustrates a common problem for non-native speakers of English" (Horn, 2012: 1). Locutions such as (53) a. He is completely unclear. b. He is fully unclear, and c. He is totally unclear, are rendered similarly into Arabic as [huwa gayru waadihin tamaaman] especially when the submodifiable adjective is gradable.

As there is no definite boarder line between 'maximizers' and 'boosters', the semantic and the pragmatic implicatures would be changed especially when some intensifiers diachronically develop their syntactic functions such as very (from modal to degree modifier) and utterly (from spatial adjunct= openly/ publicly and degree adjunct to intensifier). Paradis (1997: 81) also explains that utterly, through the course of its syntactic development combines with adjectives of an 'indeterminate character', which might indicate that "utterly may be on the way of losing some of its maximizer bias and becoming more booster-like." The example below shows that this intensifier cannot only describe gradable adjectives (a feature of maximizers), but also non-gradable ones (a feature of boosters) such as 'beautiful': (54) "My pleasures are utterly beautiful, Balthazar." (Citation of this example is from Mendez-Naya, 2012: 371.). When such shifts in syntactic structures co-occur, they definitely influence the illocutionary force of the utterance. Belonging to two or more semantic categories overshadows the rendition of such intensifiers in Arabic unless the translator eventually infers the pragmatic meaning out of context: [balOazaar, ?asaariiri jamiilatun haqqan]. However, if we follow Mendez-Naya that "Utterly typically collocates with negative heads " (2012: 373), then its Arabic version would be [?asaaririi jamiilatun bi-i-fraat], i.e., it retains its negative flavor though followed by non-gradable adjective. However, such translation is semantically ill-formed because Arabic does not prefer negative modifier collocating with positive head, and as we believe, it is a universal characteristic among languages where English is one.

\section{(d) the multi-function of intensifiers}

Having more than one contextual meaning, each intensifier genuinely influences the locution where it comes, and thus affects its illocutionary act to result in different interpretations and perlocutionary effects, in the end. Folgado (2001:130) emphasizes this point: "the issue of intensifiers is a somewhat difficult and slippery matter for the translation since what is often at stake is in fact a question of 'more or less' depending on contextual assumptions." Of course, the translator's task is somehow difficult to manage such discrepancies, and smooth away the dual function of the intensification utterance. Consider the following remarks of President Obama addressing Iran in one of his speeches in Cairo Egypt, June 4, 2009: (55) "That commitment is at the core of the Treaty, and it must be kept for all who fully abide by it." The speaker's intention is to send several 'messages' to several addressees. The use of the intensifier fully is to emphasize the intended illocutionary forces and to fully accomplish the speaker's perlocutionary effects on the part of the target hearers/readers. From the political point of view, the speaker was 'inviting', 'warning', 'asking', 'blaming' or even 'threatening' Iran if not keeping its commitment to the Nuclear Non-Proliferation Treaty.

A compromise should therefore be aimed at by the translator to account for all these illocutionary functions. Recognition of such functions requires first and foremost a pragmatic knowledge, relevant contextual factors and linguistic competence from the translator as a first reader, and s/he has to manage the pragmatic discrepancies between SL and TL. It also requires from the intended target recipients their communicative expectations and presuppositional knowledge said. The remarks might be translated into Arabic as [Jaalika l-?iltizaam huwa jawharu muçaahadati hażr ?intišaar l-?asliḩati l-nawawiyati wa-yajib l-muhaafazati çalayha bilkaamil min ladun jamiiçu ?ulaa?ika l-laðiina waqqaçu çalayha]. However, it seems difficult to achieve all the speaker's communicative intentions when faulty recognition of such intentions which in turn results in a deficient and an unwanted perlocutionary effect. Of course, such intentions depend heavily on the translator's interpretation of the intended message.

\section{Concluding Remarks}

The special restrictions and the limitations of usages of English intensifiers to a small number of syntactic combinations give a clear image of their syntactic behavior in the English grammar. The use of one intensifier rather than the other indicates the jostling of these intensifiers to win the native speakers' preference to produce English utterances including them. Moreover, their specific structural functions exclusively impose their collocational behavior on the reconstruction of English sentences.

The semantic taxonomy of English intensifiers as 'amplifiers' and 'downtoners' is not firmly fixed since some of these intensifiers have undergone a change in their original semantic and syntactic functions such as very, really and utterly. However, certain intensifiers which collocate with negative submodifiable heads retain their negative semantic aspect, though collocation with positive heads are also found like terribly nice, dreadfully happy and awfully good.

The relation between linguistic intensification and hyperbole is an intricate one and highly depends on the speaker's taste, feelings and attitude towards some real state of affairs or facts. The use of 'maximizers' or 'boosters' to up-ordowngrade a certain linguistic situation expresses a form of extremity and exaggeration to either maximize or 
minimize the meaning of certain contexts with the high degree of surplus the information to hyperbolically provide some relevant effects on the addressee.

To highly recognize the illocutionary intention of the speaker, there must be a magnificently shared knowledge of the locution types first, the knowledge of the context second, the knowledge of the communicative interaction third, and the ability to balance all these factors on the part of the sender and the receptor of the utterance, fourth. Then uncovering the transfer potentials inherited in the English intensifiers and their locutions will vouch for correct translation where the major stumbling-blocks between the SL and TL can be overcome. Moreover, the conveyance of certain speech acts is influenced by the effects which English intensifiers generate in certain contexts.

Transmission of hyperbolic functions and illocutionary forces of linguistic structures of intensification from the SL into the TL is intensely influenced by certain socio-cultural elements and syntactic locutions as well. Therefore, a failure to understand the essential structural elements of the source utterance which are the keys to the comprehension of its semantic content may result in infelicitous shifts in the sense and conventions of the target rendition of that utterance. Moreover, Arabic is a sematic language which gives a lot of emphasis on hyperbolic lexical items following special phonological rhythmic units and certain syntactic metrical scales, on one hand. On the other hand, the processing of the SL hyperbolic utterances and the reverbalization of the TL ones operate successfully on three levels: the pragmatic relevant information, the translator's awareness of linguistic and socio-cultural divergences between English and Arabic, and the TL readers' decoding and recognizing the inferences cues that help them adequately understand the communicative acts. From a pragmatic point of view, this suggests that it is not necessary that we have to render the English locutions of intensification into their Arabic counterparts as such, and hence a rejection of the equivalent approach of translation is at hand. Instead, they can be compensated by other linguistic means, and there should be some adjustments in the TL version to achieve a similar effect of English utterances on SL hearers/ readers to that on TL hearers/readers in spite of a zero realization of these intensifiers.

The relative scalar value of English intensifiers, their slippery nature of meaning, belonging to more than one semantic category, multi-function, vagueness and fuzziness of their semantic content in addition to their syntactic divergences altogether form real obstacles in a way of their rendition into Arabic. However, such rendition is possible when resemblance of the source and the target communicative acts is achieved with varying degrees, i.e., sometimes Arabic version exceeds its English counterpart in its hyperbolic function, and the opposite is true.

\section{References}

Al-Hashimi, A. (1963). Jawaahir l-Balaaghati fi-l-Ma'aani wa-l-Bayaan wa-l-Badii' [Jewels of Eloquence in Meanings, Clarity, and Rhetoric ]. Cairo: Al-Maktabatu 1-Tijaariyatu 1-Kubraa.

Attamimi, F. (2011). Analysis of misunderstanding caused by different interpretations of speech act labels in Tintin and Asterx Comic Series. K@ta 13.1:78-95.

Bernardo, A. (2010). Translation as text transfer-pragmatic implications. Estudos Linguisticos 5:107-115.

Biber, D., S. Johansson, G. Leech, S. Conrad and E. Finegan (1999) The Longman Grammar of Spoken and Written English. London: Longman.

Bolinger, D. (1972). Degree Words. The Hague and Paris: Mouton.

Bruti, S. (2006). Cross-cultural pragmatics: the translation of implicit compliments in subtitles. The Journal of Specialized Translation 6:185 - 197.

Carston, R. (1991) Implicature, explicature and truth-theoretic semantics. Pragmatics: A Reader 6: 33-51.

Colston, H.L. and Keller,S.B. (1998). You'll never believe this: irony and hyperbole in expressing surprise. Journal of Paralinguistic Research 27.4: 499-513.

Folgado, V. L. (2001). Interpretive use: translating intensification. Revista Alicantide Estudios Ingleses 14:123-135.

Horn, F. (2012). Is it fully, completely or totally aware? Validating collocation candidates using statistical measures. [Online] Available: http://linglit194.linglit.tu-darmstadt.de/ (April 30, 2012) 1-11.

Hussein, T. (n. d.). Al-Ayyam [The Days], pts.1-3. Cairo: Daaru 1-Ma'aarif.

(1997). [1932] An Egyptian Childhood. (translated by E.H. Paxton) The Days, pt.1. Cairo:The American University Press.

Josiah,Y. and Johnson, S. (2012). Pragmatic analysis of President Goodluck Jonathan's and President Barack Obama's inaugural address. International Journal Social Science 2.12: 261-278.

Lenci, A. (1994). A relevance-based approach to speech acts. Paper presented at The Workshop on Speech Acts and Linguistic Research. Buffalo NY, July 15-16,115-124.

Mahfoudh, N. (1972). Ziqaaq Al-Midaq [Midaq Alley]. Cairo: Daaru 1-Qalam ( translated by Trevor le Gassick).

Mahmood, A. and Abdellatif, K. (2010). Translation of parodies in Terry Pratchette's 'Witches Abroad' and 'Wyrd Sisters' into German. Jordan Journal of Applied Science 12.1:145-168.

Mendez-Naya, B. (2008). Special issue on English intensifiers. English Language and Linguistics 12. 2: 213 -219. 
(2012). A preliminary study of the history of intensifier 'Utterly'. In M. A. Sara et al.(eds.), A Time of Crisis: English and American Studies in Spain. Barcelona: AEDEAN. 368-375.

Mustonen, M. (2010). A Multivariable Corpus Study on Intensifiers in British English. M.A. Thesis, University of Eastern Finland. [Online] Available: .http://epublications.uef.fi/pub/urn_nbn_fi_uef-20100090 (July 13, 2012).

Paradis, C. (1997). Degree Modifiers of Adjectives in Spoken British English. Lund: Lund University Press.

Partington, A. (1993). Corpus evidence of language change: the case of the intensifier. In M. Baker, F. Gill and E. Tognini-Bonelli, (eds.), Text and Textology. Amsterdam: John Benjamins. 177-192.

Quirk, R., S. Greenbaum, G. Leech, and J. Svartvik (1987). A Comprehensive Grammar of the English Language. London: Longman.

Searle, J. (1976). A Classification of illocutionary acts. Language in Society 5:1-23 .

Shunnaq, A. (2000). Arabic-English translation of political speeches. Perspectives 8. 3: 207-228.

Tao, H. (2007). A corpus-based investigation of 'Absolutely' and related phenomena in spoken American English. Journal of English Linguistics 35.1: 5-29.

The Guardian, Wed., 7 Nov., 2012. [Online] Available: http://www.guardian.com.uk. (Dec. 4, 2012).

The Holy Qur'an (n. d.). K.S.A.: Majma' 1-Malik Fahd li-Tibaa'at 1-Mushaf 1-Shareef.

The Oxford English Dictionary (2000). Oxford: Oxford University Press. [Online] Available: http://www.oed.com (July 12, 2012).

Translation of the Meanings of The Noble Qur'an in the English Language (1999) K.S.A.: King Fahd Complex for Printing of The Holy Qur'an. 